\title{
Expression profiling of immune inhibitory Siglecs and their ligands in patients with glioma
}

\author{
Kim C. M. Santegoets ${ }^{1}$. Paul R. Gielen ${ }^{1}$. Christian Büll ${ }^{1}$ Barbara M. Schulte ${ }^{1}$ - Esther D. Kers-Rebel ${ }^{1}$. \\ Benno Küsters ${ }^{2} \cdot$ Sandra A. J. F. H. Bossman ${ }^{3} \cdot$ Mark ter Laan $^{3} \cdot$ Pieter Wesseling ${ }^{4,5} \cdot$ Gosse J. Adema ${ }^{1}$
}

Received: 14 June 2018 / Accepted: 24 March 2019 / Published online: 5 April 2019

(c) The Author(s) 2019

\begin{abstract}
Gliomas appear to be highly immunosuppressive tumors, with a strong myeloid component. This includes MDSCs, which are a heterogeneous, immature myeloid cell population expressing myeloid markers Siglec-3 (CD33) and CD11b and lacking markers of mature myeloid cells including MHC II. Siglec-3 is a member of the sialic acid-binding immunoglobulin-like lectin (Siglec) family and has been suggested to promote MDSC expansion and suppression. Siglecs form a recently defined family of receptors with potential immunoregulatory functions but only limited insight in their expression on immune regulatory cell subsets, prompting us to investigate Siglec expression on MDSCs. We determined the expression of different Siglec family members on monocytic-MDSCs (M-MDSCs) and polymorphnuclear-MDSCs (PMN-MDSCs) from blood of glioma patients and healthy donors, as well as from patient-derived tumor material. Furthermore, we investigated the presence of sialic acid ligands for these Siglecs on MDSCs and in the glioma tumor microenvironment. Both MDSC subsets express Siglec-3, -5, -7 and -9, with higher levels of Siglec-3, -7 and -9 on M-MDSCs and higher Siglec-5 levels on PMN-MDSCs. Similar Siglec expression profiles were found on MDSCs from healthy donors. Furthermore, the presence of Siglec-5 and -9 was also confirmed on PMN-MDSCs from glioma tissue. Interestingly, freshly isolated glioma cells predominantly expressed sialic acid ligands for Siglec-7 and -9, which was confirmed in situ. In conclusion, our data show a distinct Siglec expression profile for M- and PMN-MDSCs and propose possible sialic acid-Siglec interactions between glioma cells and MDSCs in the tumor microenvironment.
\end{abstract}

Keywords Myeloid-derived suppressor cells $\cdot$ Glioma $\cdot$ Siglecs $\cdot$ Sialic acids

\begin{tabular}{|c|c|c|}
\hline & Abbreviation & \\
\hline & e-MDSC & $\begin{array}{l}\text { Early-stage myeloid-derived suppressor } \\
\text { cell }\end{array}$ \\
\hline & IDH & Isocitrate dehydrogenase \\
\hline $\begin{array}{l}\text { Note on previous publication Parts of this paper are based on } \\
\text { the work described in the PhD thesis of Paul R. Gielen entitled }\end{array}$ & ITIM & $\begin{array}{l}\text { Immunoreceptor tyrosine-based inhibitory } \\
\text { motif }\end{array}$ \\
\hline $\begin{array}{l}\text { 'The immunosuppressive network in patients with glioma; } \\
\text { focus on the role of myeloid-derived suppressor cells', Radboud }\end{array}$ & M-MDSC & $\begin{array}{l}\text { Monocytic myeloid-derived suppressor } \\
\text { cell }\end{array}$ \\
\hline University, Nijmegen, The Netherlands, 2016 [1]. Figures 1, 2, 3 & MALII & Maackia amurensis lectin II \\
\hline with some adjustments and/or additional data. & PMN-MDSC & Polymorphonuclear myeloid-derived sup- \\
\hline Electronic supplementary material The online version of this & PNA & Peanut agglutinin \\
\hline article (https://doi.org/10.1007/s00262-019-02332-w) contains & Radboudumc & Radboud University Medical Center \\
\hline supplementary material, which is avallable to autnorized users. & Siglec & Sialic acid-binding immunoglobulin-like \\
\hline Kim C. M. Santegoets and Paul R. Gielen contributed equally to & & lectin \\
\hline this paper and are joint first authors. & SNA-I & Sambucus nigra agglutinin \\
\hline 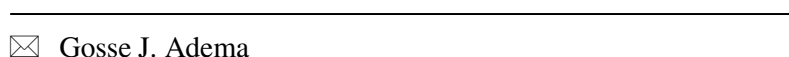 & S100A8 & S100 calcium-binding protein A8 \\
\hline
\end{tabular}

Gosse.Adema@radboudumc.nl

Extended author information available on the last page of the article 


\section{Introduction}

Gliomas are the most common primary brain tumors in adults arising from (precursors of) glial cells [2]. Most of these tumors show extensive ('diffuse') infiltration in the brain parenchyma, which precludes complete surgical resection. Even after state-of-the-art radio- and chemotherapy following surgical resection to the maximum feasible extent, patients with a glioblastoma (i.e., by far the most frequent and most malignant form of astrocytoma) have a dismal prognosis of only 14-16 months [3, 4].

At the moment, there are no effective FDA-approved treatment options available for radio- and chemotherapyresistant gliomas. Cancer immunotherapy, where the patient's own immune system is used to eradicate tumor cells, may provide a promising approach to specifically destroy glioma cells without harming the surrounding brain tissue. Numerous immunotherapies are currently being investigated in patients with glioma, but so far, the induction of tumor cell-specific cytotoxic T cells and survival benefit are only found in a minority of patients [5-7]. Gliomas often show a strong immunosuppressive tumor microenvironment with many suppressive immune cells including myeloid-derived suppressor cells (MDSCs), tumor-associated macrophages and regulatory $\mathrm{T}$ cells. This hampers immune cell function and limits the efficacy of cancer (immuno)therapies [7-10]. Therefore, combination therapies are now being actively investigated aiming to activate the immune system and to limit the immunosuppressive tumor microenvironment, in which myeloid cells are thought to play an important role.

We and others have previously reported an increase of MDSCs in the blood of glioma patients [11-13]. MDSCs express the myeloid lineage markers Siglec-3 (CD33) and CD11b but lack markers of mature myeloid cells (MHC II molecules HLA-DR,DP,DQ) [14, 15]. There are two main MDSC populations, a monocytic (M-) and a polymorphonuclear (PMN-) MDSC population, which are defined by the expression of CD14 or CD15, respectively. In addition, a third subset has been suggested that is lacking the myeloid cell lineage markers CD15 and CD14. This is a mixed population of early progenitor cells and is, therefore, called early-stage MDSCs (e-MDSCs) [14, 16].

Both M-MDSCs and PMN-MDSCs are elevated in the blood of glioma patients, with PMN-MDSCs being the main MDSC population detected in the tumor tissue [11, 17]. We have previously shown that PMN-MDSCs from glioma patients are potent inhibitors of T-cell function that possibly contributes to the immunosuppressive microenvironment [13]. To interfere with their immunosuppressive function, more knowledge about the induction of MDSCs and their suppressive phenotype is needed. One of the cell surface markers used to identify MDSCs is Siglec-3, a member of the sialic acid-binding immunoglobulinlike lectin (Siglec) family [18]. Interestingly, triggering of Siglec-3 in MDSCs has been shown to promote their expansion and induce the secretion of immunosuppressive cytokines [19].

The human Siglec family consists of 14 members and can be divided into two groups: the conserved Siglecs and the CD33-related Siglecs. Conserved Siglecs (-1, -2, -4, -15) show a high sequence similarity across species, whereas CD33-related Siglecs $(-3,-5$ to $-11,-14$ and -16) display high sequence variability across species [20-22]. Siglecs are broadly expressed throughout the immune system, but which Siglecs are expressed by MDSCs apart from Siglec-3 is largely unknown. Siglecs are type-I transmembrane proteins with an extracellular sialic acid-binding domain and most of them contain a cytoplasmic immunoreceptor tyrosine-based inhibitory motif (ITIM). Their ligands are sialic acid sugars which are located on glycans of membrane glycoproteins and glycolipids of virtually all cells in the human body. Sialic acids play an important physiological role at the molecular (e.g., regulation of glycoprotein stability and function) and cellular level (e.g., cell-cell interactions) [23, 24]. Sialic acids can interact with Siglecs on the same cell surface in cis or on other cells in trans. In general, the interaction between a Siglec with its sialic acid ligand initiates an ITIM-mediated suppressive signal $[21,22]$. Thereby, Siglecs can dampen immune cell activation and possibly contribute to immunological homeostasis [21, 25]. Recent examples demonstrate the strong immunosuppressive capacity of Siglecs. For instance, sialic acid binding to Siglec- 2 on B cells has been shown to suppress B-cell activation and induces tolerance to membrane antigens [26, 27]. Furthermore, we have recently shown that monocytic cell activation can be dampened via Siglec-3 triggering [28].

A growing body of evidence suggests that tumor cells exploit the Siglec family to modulate immune cell function and to evade detection by the immune system [29-36]. Tumor sialic acids have been shown to dampen NK cellmediated killing via Siglec-7 and -9 as well as effector T-cell function [31, 32, 37]. Furthermore, triggering of Siglec-9 on macrophages by tumor-derived sialic acids induced a tumorassociated macrophage-like phenotype promoting immune suppression in the tumor microenvironment [33]. These studies suggest that tumor-derived sialic acids modulate the function of effector and regulatory immune cell subsets by interacting with the Siglec receptor family. To what extent sialic acid-Siglec interactions could influence MDSC function in the tumor microenvironment is largely unknown. Therefore, we assessed the expression of Siglec family members on MDSCs from glioma patients and healthy donors. In addition, the expression of putative cis and trans sialic acid 
ligands on MDSCs and glioma cells in the tumor microenvironment was analyzed.

We found that M- and PMN-MDSCs from blood of glioma patients and healthy donors express multiple Siglecs with specific expression profiles, while e-MDSCs show only little to no Siglec expression. This could be confirmed on glioma-infiltrating PMN-MDSCs. Subsequently, we identified expression of putative trans Siglec ligands on glioblastoma cell lines as well as in patient-derived glioma tissue. These data support possible sialic acid-Siglec interactions between MDSCs and glioma cells, which could contribute to the immunosuppressive role of MDSCs in glioma patients.

\section{Materials and methods}

\section{Blood and tumor samples}

Peripheral blood samples were collected from 14 healthy individuals and from 18 glioma patients undergoing neurosurgical resection or biopsy for intracranial tumors at the Radboud University Medical Center (Radboudumc). The mean age of the patients was 58 years (range 43-76 years) and $56 \%$ were males. The healthy donors were anonymous and not age and sex matched. All patients had histologically proven brain tumors diagnosed by neuropathologists of the Radboudumc. The tumors were classified according to the WHO 2016 Classification of tumors of the Central Nervous System [38], and encompassed 1 low-grade diffuse astrocytoma, Isocitrate dehydrogenase (IDH)-mutant (WHO grade II), 6 oligodendrogliomas, IDH-mutant and 1p/19qcodeleted (2 WHO grade II, 4 WHO grade III), 2 glioblastomas, IDH-mutant, and 9 glioblastomas, IDH-wildtype. Fresh tumor tissue samples were obtained from 6 patients by sonic aspiration [3 oligodendrogliomas ( 2 WHO grade II, 1 WHO grade III) and 3 glioblastomas (2 IDH-wildtype, 1 IDH-mutant)]. In addition, histological sections of formalinfixed paraffin-embedded glioma tissue were obtained from 4 patients with glioblastoma (3 IDH-wildtype, $1 \mathrm{IDH}$-mutant). Ten patients had started a $3 \times 5 \mathrm{mg}$ dexamethasone regime on the day before surgery, while 8 patients received dexamethasone at an earlier time point to reduce edema. Immediately after the blood and fresh tumor tissue samples were obtained, processing of these samples was started. Flow cytometry measurements were performed within $24 \mathrm{~h}$.

\section{Tissue handling}

PBMCs were isolated from heparinized venous blood of patients and healthy donors using a lymphoprep gradient (Lucron Bioproducts, Gennep, the Netherlands). Fresh glioma material was obtained by ultrasonic aspiration or excision. Ultrasonic aspirates were collected in a sterile suction trap and tumor cell suspensions were prepared as described previously [11, 39]. Briefly, tumor fragments were washed extensively to discard blood and suction fluid. Then, tumor fragments were incubated with collagenase type-IA (50 $\mu \mathrm{g}$ / ml) (Sigma-Aldrich, St Louis, MO), DNAse type-I (10 $\mu \mathrm{g} /$ $\mathrm{ml}$ ) (Roche, Mannheim, Germany) and trypsin inhibitor $(1 \mu \mathrm{g} / \mathrm{ml})$ (Sigma-Aldrich) in Hank's Balanced Salt Solution (HBSS) (Gibco, Invitrogen, Leek, the Netherlands) at $37{ }^{\circ} \mathrm{C}$ followed by mechanical disruption by pipetting. To remove granulocytes, including mature neutrophils, tumor cell suspensions were placed on a lymphoprep gradient as was also used for PBMC isolation.

\section{Flow cytometry and sorting}

Using standardized flow cytometry protocols as described previously, cells were stained for different membrane markers using regular antibodies as well as with lectins and recombinant Siglec-Fc chimeras to determine their sialic acid composition $[11,28]$. To exclude dead cells, the cells were stained with fixable viability dye eFluor 780 (eBioscience, Vienna, Austria). Prior to staining, Fc receptors were blocked by incubation with $2 \%$ human serum. Membrane markers and Siglecs were stained with directly conjugated monoclonal antibodies (mAbs) for $20 \mathrm{~min}$ on ice. Fluorescent mAbs were obtained from BD (San Jose, CA) (CD33-APC, HLA-DR,DP,DQ-FITC, CD14-PerCP), Pelicluster (Amsterdam, the Netherlands) (CD14-PE), IO-Test (CD11b-PE), Biolegend (San Diego, CA) (CD15-PE-Cy7, CD45-PerCP, Siglec-5-PE, Siglec-7-PE, Siglec-10-PE), Sigma-Aldrich (Siglec-2-PE) and R\&D Systems (Siglec9-PE). Isotype controls were obtained from BD (IgG1-APC, IgG1-PE-Cy7, IgG2a-PE, IgG2a-FITC, and IgG1-PE) and Biolegend (IgG2a-PerCP). Cells were washed and resuspended in PBS with $1 \%$ BSA and $0.02 \%$ sodium azide and measured on a CyAn (Beckman Coulter, Brea, CA), FACSVerse (BD) or Gallios (Beckman Coulter) flow cytometer. For lectin staining, cells were stained with biotinylated lectins Maackia amurensis lectin II (MALII), Sambucus nigra agglutinin (SNA-I) and peanut agglutinin (PNA) in carbofree blocking solution containing $1 \mathrm{mM} \mathrm{CaCl}{ }^{2+}$ and $1 \mathrm{mM}$ $\mathrm{MgCl}^{2+}$ (Vector Laboratories, Burlington, NO) for $40 \mathrm{~min}$. After washing, the cells were incubated with PE-conjugated Streptavidin (BD, Franklin Lakes, NJ). For Siglec ligand staining, $0.4 \mu \mathrm{g} / \mathrm{ml}$ recombinant human Siglec-Fc chimera (R\&D Systems, Minneapolis, MN) was pre-complexed with with Alexa Fluor 647-conjugated goat anti-human IgG $(\mathrm{H}+\mathrm{L})$ antibody (Life Technologies, Burlington, Ontario, Canada) in carbo-free blocking solution containing $1 \mathrm{mM}$ $\mathrm{CaCl}^{2+}$ and $1 \mathrm{mM} \mathrm{MgCl}^{2+}$ and added to the cells for $40 \mathrm{~min}$ at $4{ }^{\circ} \mathrm{C}$. Cells incubated with Alexa Fluor 647 goat antihuman IgG antibody only served as control. Data were analyzed using FlowJo 9.2 (Tree Star Inc, Ashland, OR) and 
events were gated on single viable cells for further analysis. Median fluorescence intensity (MFI) values of Siglec stainings were corrected based on the MFI values of the isotype controls to control for flow cytometer type. For sorting of MDSC subsets, PBMCs were stained with HLA-DR,DP,DQFITC, CD33-APC, CD14-PE and CD15-PE-Cy7 and sorted on a FACS Aria (BD). Data were analyzed using GraphPad Prism 5 software.

\section{Quantitative PCR}

FACS-sorted cells were resuspended in RNA lysis buffer (Zymo Research, Irvine, CA) and stored at $-80{ }^{\circ} \mathrm{C}$ until RNA isolations were performed using the ZR RNA isolation kit (Zymo Research), according to the manufacturer's instructions. The RNA was treated with DNAase I (amplification grade; Invitrogen) to remove any genomic DNA before being reverse-transcribed into cDNA, as described elsewhere [40]. To check for genomic DNA contamination control samples without reverse transcriptase were included. cDNA was stored at $-20{ }^{\circ} \mathrm{C}$ until further use. Real-time PCR was performed on a CFX96 system (BioRad, Veenendaal, Netherlands) using SYBR Green reaction mix (Sigma-Aldrich) and Siglec expression was calculated relative to GAPDH expression. Primer sequences (SigmaAldrich) were derived from the Harvard Primer Bank database (Supplementary Table 1) [41].

\section{Glioma cell culture}

Human glioma cell lines U-87 (HTB-14), T98G (CRL-1690) and U-251 were grown in Dulbecco's Modified Eagle's Medium (DMEM) with GlutaMAX (Gibco) supplemented with 10\% heat-inactivated FBS (Greiner Bio-one, Frickenhausen, Germany), and antibiotic-antimycotic solution (Life Technologies) to confluency and passaged using trypsin. The cells were used within 3 months after resuscitation and regularly screened for mycoplasma contamination using a detection kit (Lonza, Walkersville, MD). All cells were incubated in a humidified $\mathrm{CO} 2$ incubator at $37^{\circ} \mathrm{C}$.

\section{Immunohistochemistry}

Siglec ligand expression on paraffin-embedded glioma tissue samples $(4 \mu \mathrm{m})$ was assessed using human Siglec-Fc chimeras. Sections were deparaffinized and rehydrated with Xylene, graded ethanol and water. Sections were heated at $96{ }^{\circ} \mathrm{C}$ for $30 \mathrm{~min}$ in target retrieval solution, citrate $\mathrm{pH} 6.0$ (Dako, Agilent Technologies, Santa Clara, CA). After cooling down to room temperature, sections were treated with $3 \% \mathrm{H}_{2} \mathrm{O}_{2}$ in PBS for 15 min, washed with PBS and blocked with $20 \%$ goat serum. Siglec-7 and -9 ligands were stained with $50 \mathrm{nM}$ Siglec-Fc chimeras, pre-complexed with $20 \mathrm{nM}$ horseradish peroxidase-conjugated anti-human $\mathrm{Fc}$ antibody (Thermo Scientific, Waltham, MA) in HBSS at $4{ }^{\circ} \mathrm{C}$. Human IgG1 (Sigma-Aldrich) was used as isotype control. SiglecFc binding was detected with a DAB peroxidase substrate kit (Vector Laboratories). All tissue sections were counterstained with hematoxylin, washed with water, dehydrated and mounted with KP-mounting medium (Klinipath, Olen, Belgium). Alternatively, sections were treated with $250 \mathrm{mU} /$ $\mathrm{ml}$ Clostridium perfringens sialidase (Sigma-Aldrich) in HBSS for $2.5 \mathrm{~h}$ at $37^{\circ} \mathrm{C}$ and washed with PBS before staining with Siglec-Fc chimeras. Images were acquired using a Leica DM6000 system (Leica, Wetzlar, Germany).

\section{Results}

\section{Blood MDSCs express several Siglec family members}

Most myeloid cells express several members of the Siglec family, but not much is known about Siglec expression on MDSCs, except for Siglec-3. Therefore, we assessed the expression of the different Siglec family members on sorted M-MDSCs $\left(\mathrm{CD} 33^{+} \mathrm{MHC} \mathrm{II}^{\text {low/- }} \mathrm{CD} 14^{+}\right)$and PMNMDSCs $\left(\mathrm{CD}_{3} 3^{+} \mathrm{MHC} \mathrm{II}^{\text {low/ }}-\mathrm{CD} 15^{+}\right)$from the blood of glioma patients (Fig. 1a). In our patient cohort, M-MDSCs and PMN-MDSCs represented an average of 5.07\% $(\mathrm{SD}=6.27)$ and $3.28 \%(\mathrm{SD}=4.12)$ of PBMCs, respectively, which is in line with our previously reported data $[11,13]$. RNA analysis confirmed Siglec-3 expression by both MDSC subsets. Additionally, M-MDSCs expressed mRNA for Siglec-5, -7, -9, -10, -11, -14, and -16 with Siglec-9 showing the highest expression (Fig. 1b). PMNMDSCs showed a similar expression profile, but in contrast to M-MDSCs, they also expressed Siglec-6, and -8 at the mRNA level (Fig. 1c). Interestingly, expression of Siglec-5 was about 4 times higher in PMN-MDSCs compared to M-MDSCs. Next, we determined Siglec expression on the cell surface of M- and PMN-MDSCs from patients with glioblastomas and lower-grade gliomas by flow cytometry using available Siglec antibodies. As expected, Siglec-3 (CD33) was detected on the cell surface of both subpopulations, with a higher expression on M-MDSCs (Fig. 1a, e-f). Siglec-2, a conserved Siglec known to be B-cell specific, was included as a negative control and was not found on either M- or PMN-MDSCs (Fig. 1d-f) [21]. Siglec-5, -7 and -9 were clearly detected on both M- and PMN-MDSCs, with Siglec-5 being the most highly expressed on PMN-MDSCs (Fig. 1d-f). In contrast to the qPCR data, there was little to no expression of Siglec-10 detectable. Additional data have also shown a lack of Siglec- 6 and -8 expression on both MDSC subsets (data not shown). These data confirm that both MDSC 
Fig. 1 Siglec expression on blood MDSCs from glioma patients and healthy donors. a Gating strategy for MDSCs from blood, showing M-, PMNand e-MDSC subsets. b, c qPCR analysis of Siglec expression in M-MDSCs (b) and PMN-MDSCs (c) from glioma patients. Bar diagrams show mean relative Siglec expression normalized to GAPDH \pm SEM $(n=5)$. d-h Cell surface expression of Siglecs on MDSC subsets measured by flow cytometry. Representative histograms show cell surface Siglec expression on M-MDSCs (left panel) and PMN-MDSCs (right panel) (d). The gray histograms represent the isotype control. Dot plots show median fluorescence intensity (MFI) of cell surface Siglec expression of M-MDSCs and PMN-MDSCs derived from blood of glioma patients $(n=11-13 ; 6$ lowergrade gliomas (open circles) and 7 glioblastomas (filled circles)) (e,f) as well as from healthy donors $(n=10-14)$ (g, h). Horizontal lines show the mean Siglec expression a

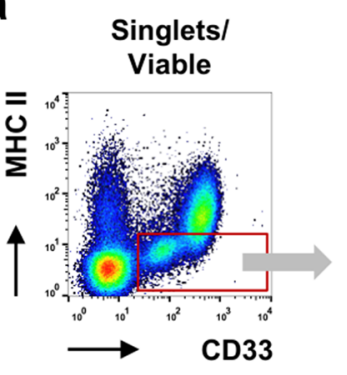

$\mathrm{CD}^{+}{ }^{+} \mathrm{MHC}$ Illow/(MDSC)

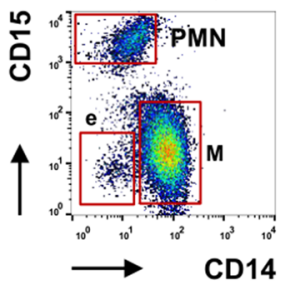

b

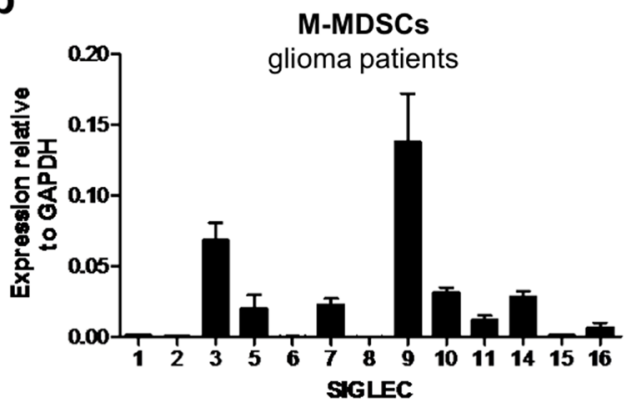

C

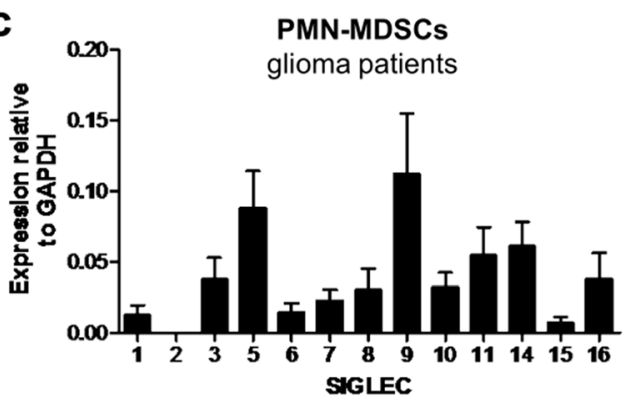

e

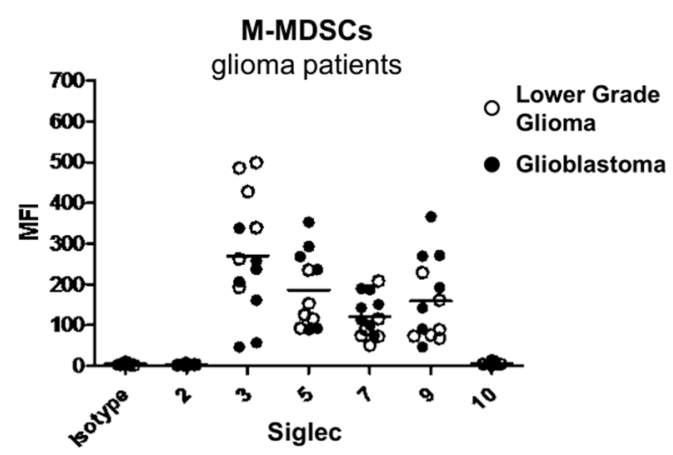

g

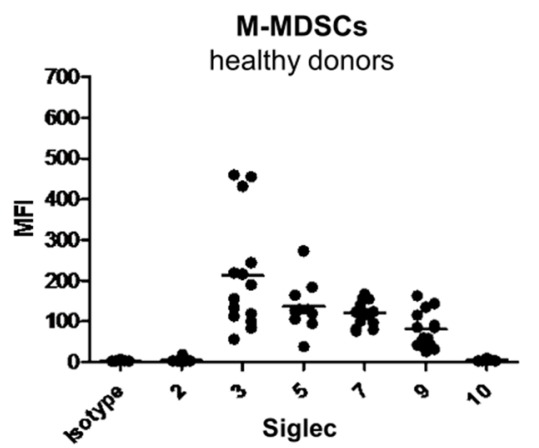

d

\section{M-MDSCs PMN-MDSCs}
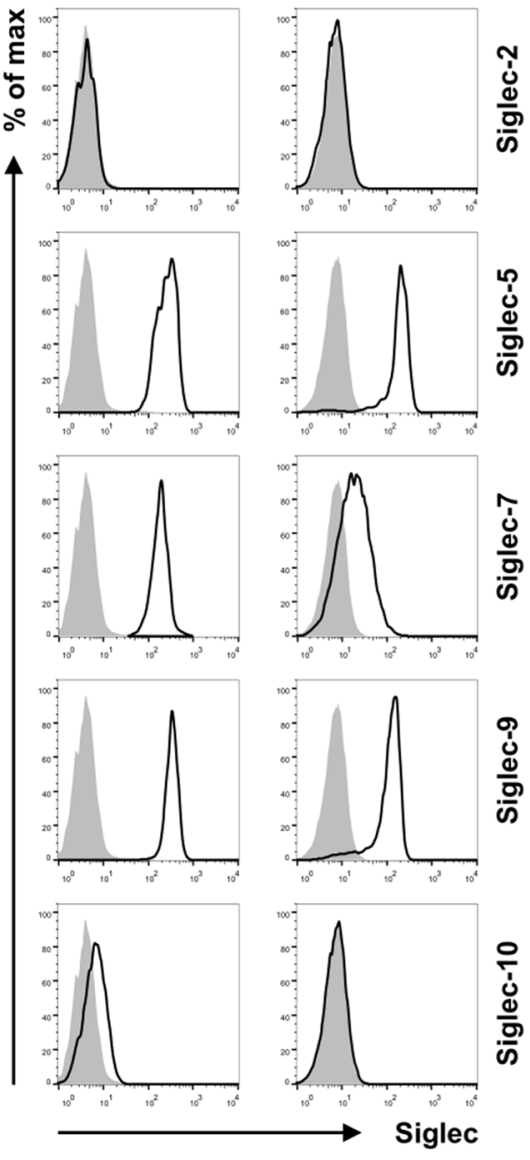

f

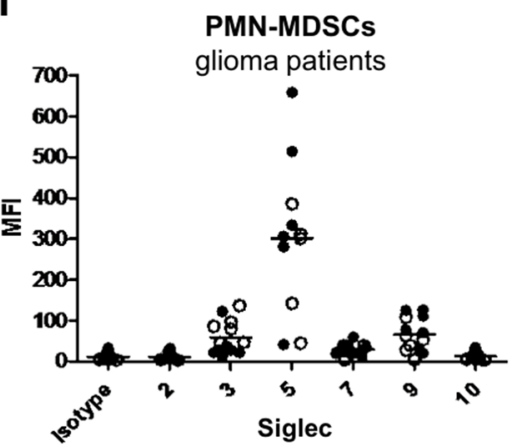

h

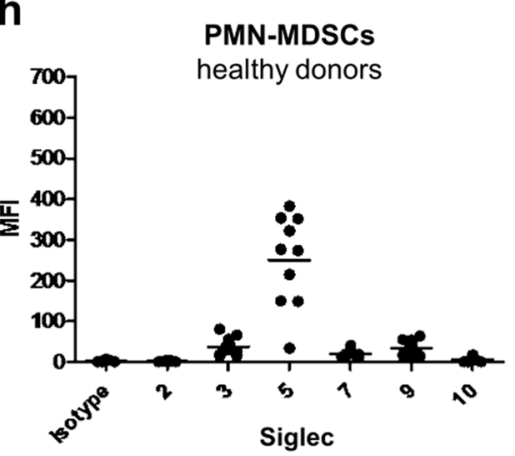


subsets express Siglec-3, $-5,-7$ and -9 , with a generally higher Siglec expression on M-MDSCs compared to PMNMDSCs, except for Siglec-5 which is highly expressed on PMN-MDSCs.

Healthy donors generally have very low amounts of MDSCs in their peripheral blood [11, 13, 16]. Nevertheless, we also determined Siglec expression on MDSCs present in healthy donors. M-MDSCs $(0.53 \%$ ( $\mathrm{SD}=0.28)$ of PBMCs) and PMN-MDSCs (2.38\% (SD =2.61) of PBMCs) from healthy donors express the same Siglecs as detected on MDSC subsets from glioma patients, with similar expression profiles (Fig. 1g, h). Thus, both M-MDSCs and PMNMDSCs express Siglec-3, -5, -7 and -9 in glioma patients as well as healthy donors, with a specific expression profile dependent on the MDSC subtype.

In addition to these M- and PMN-MDSC populations, we also analyzed Siglec expression on the CD15-CD14e-MDSCs (Fig. 1a). In our cohort, the mean percentage of this population was $0.73 \%(\mathrm{SD}=0.50)$ in glioma patients and $2.12 \%(\mathrm{SD}=2.05)$ in healthy donors. The expression of Siglec-3 on these cells is similar to PMN-MDSCs. Other than that, they show little to no Siglec expression (Supplementary Fig. 1). Therefore, we focused on M- and PMNMDSCs for further analyses.

\section{Glioma-infiltrating PMN-MDSCs express Siglec-5, -7, and -9}

We have previously characterized MDSC infiltration in glioma tissue and found mainly PMN-MDSCs $[11,13]$. Therefore, we additionally analyzed Siglec expression on gliomainfiltrating PMN-MDSCs. Single cell suspensions derived from tumor tissue were stained for PMN-MDSC markers and Siglecs. Cells were first gated on single, viable cells and CD45 expression (Fig. 2a, left panel). Then, PMN-MDSCs were identified as $\mathrm{CD} 11 \mathrm{~b}^{+} \mathrm{MHC} \mathrm{II}^{\text {low/- }} \mathrm{CD} 15^{+}$, because no clear Siglec-3 signal above background could be detected on these tumor-infiltrating MDSCs, as described previously [11]. Similar to blood PMN-MDSCs, Siglec-5 and -9 could be detected on glioma-infiltrating PMN-MDSCs, with the highest expression of Siglec-5 (Fig. 2a, b). Low Siglec-7 expression could be detected on glioma-infiltrating

a
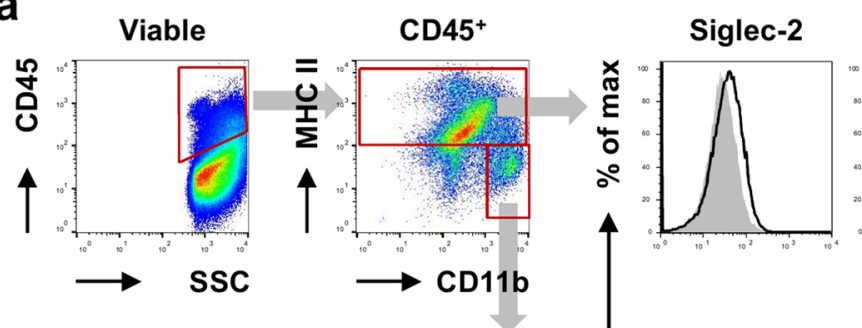

Siglec-5

Siglec-7

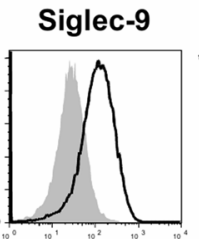

Siglec-10
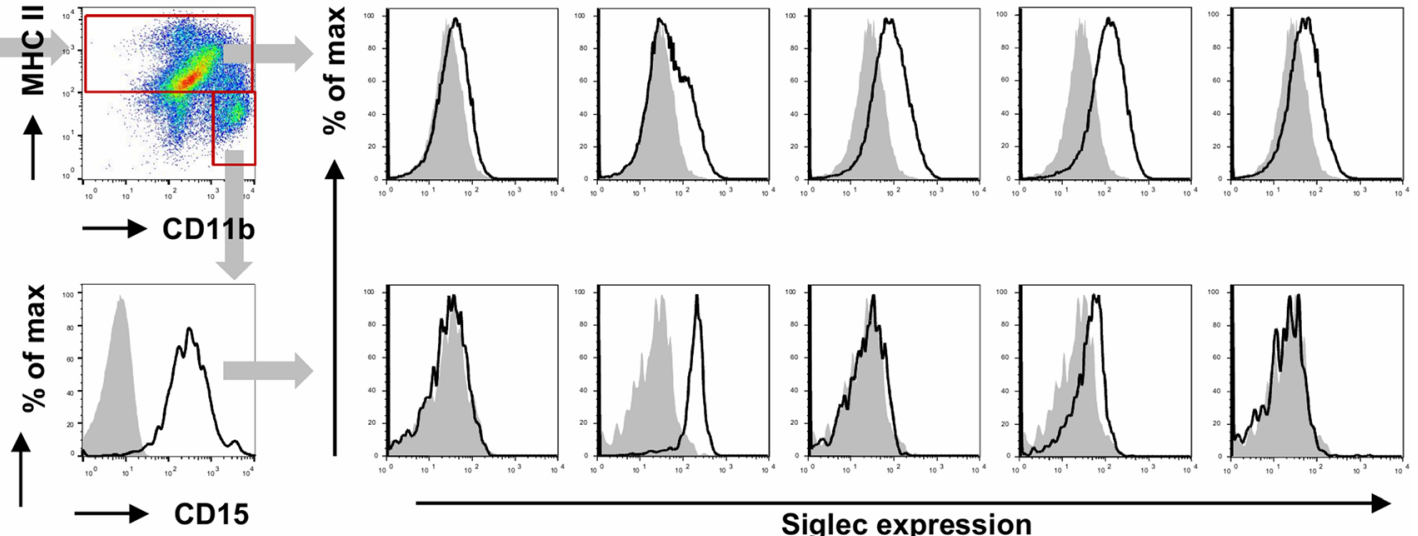

Siglec expression

b

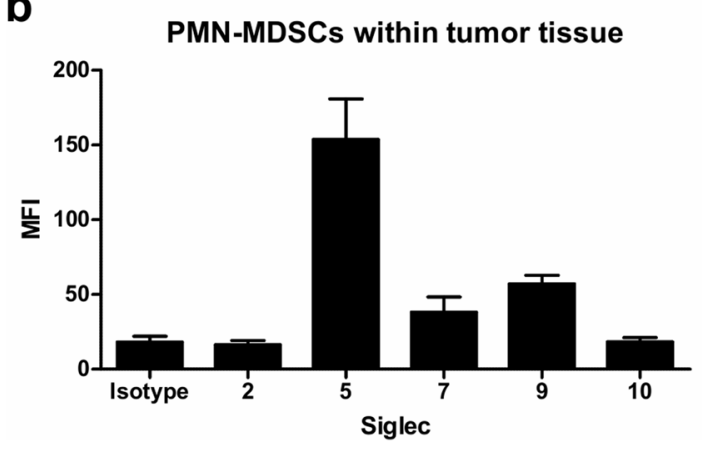

Fig. 2 Siglec expression on glioma-infiltrating PMN-MDSCs. a-c Expression of Siglecs on the surface of PMN-MDSCs and myeloid cells in glioma tissue. Gating strategy shows $\mathrm{CD}^{+} 5^{+} \mathrm{MHC} \mathrm{II}^{+}$ $\mathrm{CD}_{11 b^{+}}$myeloid cells and $\mathrm{CD} 45^{+} \mathrm{MHC} \mathrm{II}^{-} \mathrm{CD} 11 \mathrm{~b}^{+} \mathrm{CD} 15^{+} \mathrm{PMN}-$ MDSCs (a, left panels). Representative histograms show Siglec

C

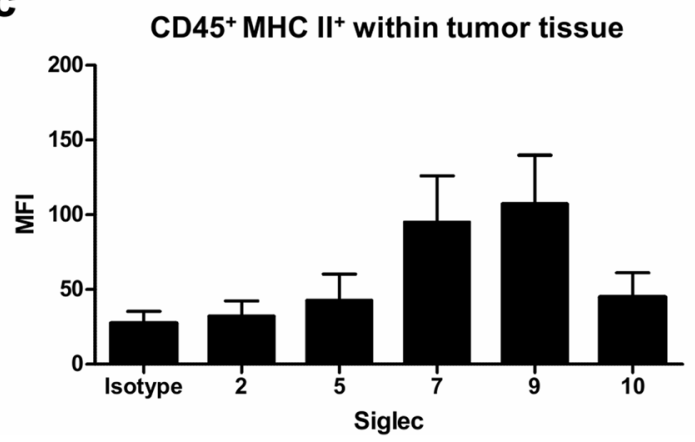

expression on myeloid cells (a, upper panel) and PMN-MDSCs (a, lower panel). The gray histograms represent the isotype control. b, c Bar diagrams show mean Siglec expression \pm SEM on gliomainfiltrating PMN-MDSCs (b) and myeloid cells (c) from three glioma patients 
a

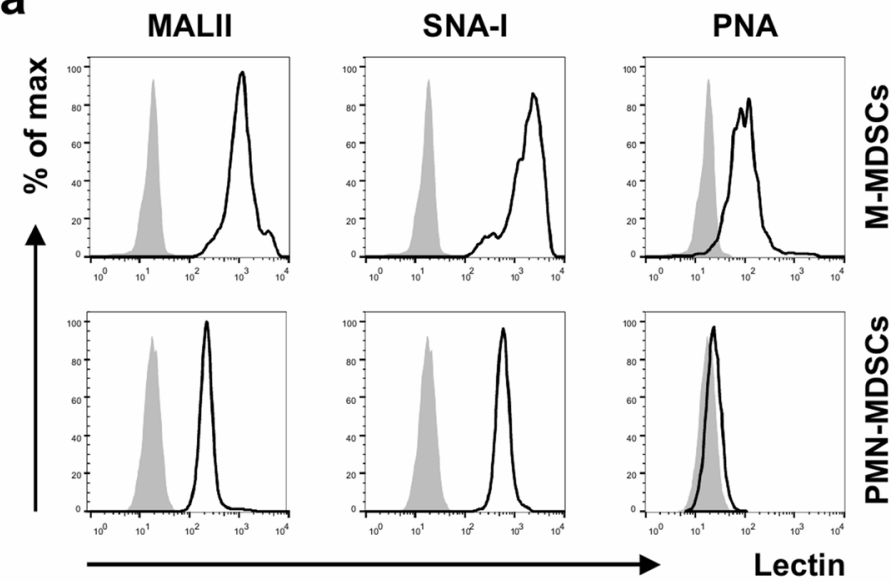

b

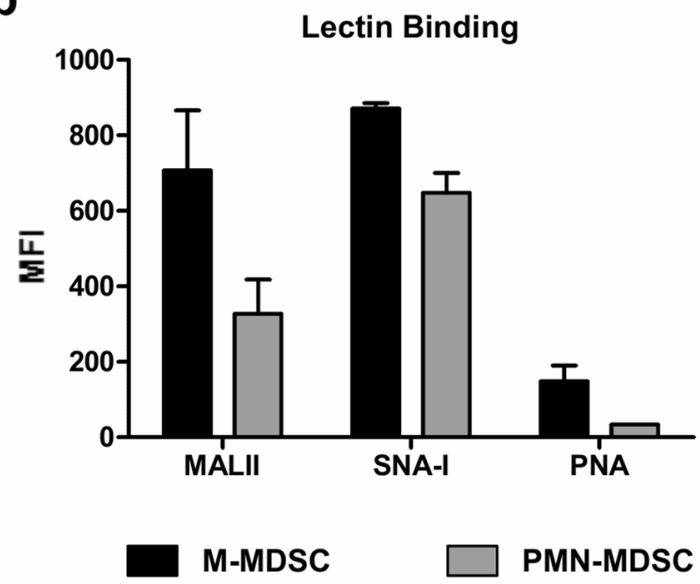

C

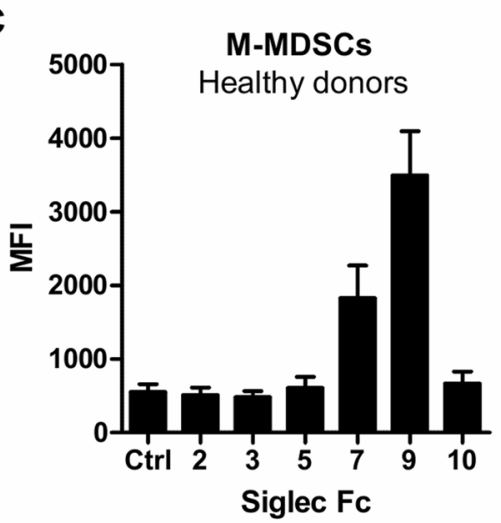

f

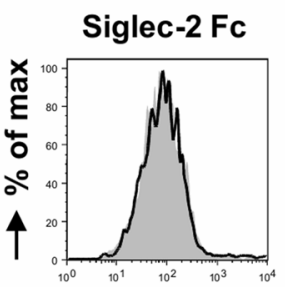

Siglec-3 Fc

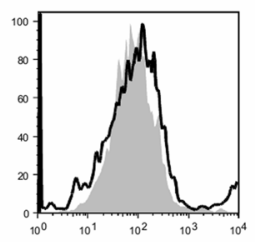

d

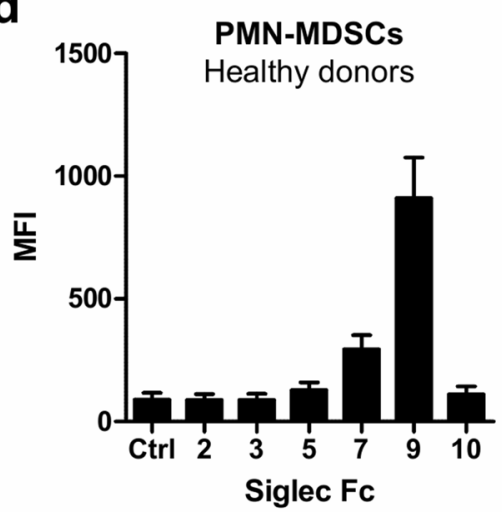

Siglec-5 Fc

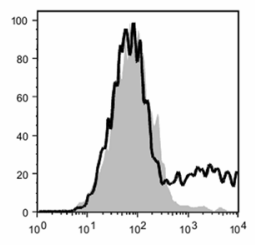

Siglec-7 Fc

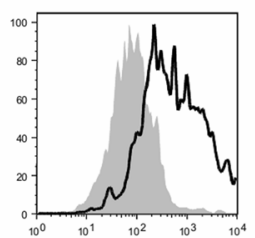

e

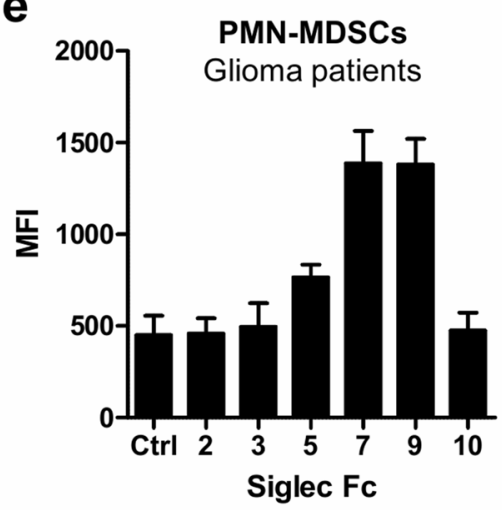

Siglec-9 Fc

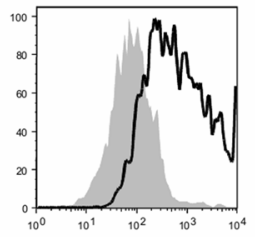

Siglec-10 Fc

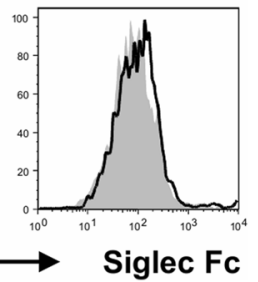

Fig. 3 Expression of sialic acids on blood MDSCs from healthy donors and glioma patients. a, b Binding of sialic acid-binding lectins MALII ( $\alpha 2,3$-linked sialic acid) and SNA-I ( $\alpha 2,6$-linked sialic acid) and galactose-binding lectin PNA to MDSCs isolated from blood of healthy donors. a Representative histograms show lectin binding to M-MDSCs (upper panel) and PMN-MDSCs (lower panel) as determined by flow cytometry. The gray histograms represent the unstained control b) Bar diagram shows MFI \pm SEM of lectin binding

PMN-MDSCs in some patients, while on others it was undetectable (Fig. 2a, b). Besides PMN-MDSCs, a group of $\mathrm{CD} 45^{+} \mathrm{CD} 1 \mathrm{~b}^{+} \mathrm{MHC} \mathrm{II}^{+}$myeloid cells is present in glioma tissue that consists of tumor-infiltrating monocytes, tumor-associated macrophages and/or microglia. This group expressed Siglec-7 and -9 to a similar extent as $\mathrm{CD} 33^{+} \mathrm{MCH}$ $\mathrm{II}^{+}$cells from blood, but displayed lower levels of Siglec-5 (Fig. 2a, c, Supplementary Fig. 2). Altogether, these data to both MDSC subsets $(n=3)$. c, $\mathbf{d}$ Binding of recombinant Siglec Fc chimera to MDSCs from healthy donors $(n=3)$. Bar diagrams shows $\mathrm{MFI} \pm$ SEM of Siglec Fc binding to M-MDSCs (c) and PMN-MDSCs (d). e, f Siglec ligand expression on PMN-MDSCs obtained from the blood of glioma patients $(n=5)$. Bar diagram shows Siglec Fc binding as MFI \pm SEM (e) and histograms show representative Siglec Fc binding (f). The gray histograms represent the isotype control

show that glioma-infiltrating PMN-MDSCs consistently express Siglec-5 and -9, while other myeloid cells in the tumor mainly express Siglec-7 and -9 .

\section{MDSCs express cis Siglec ligands}

We next investigated the expression of sialic acids on MDSCs using the lectins MALII, SNA-I and PNA. These 
a

Glioblastoma cell lines

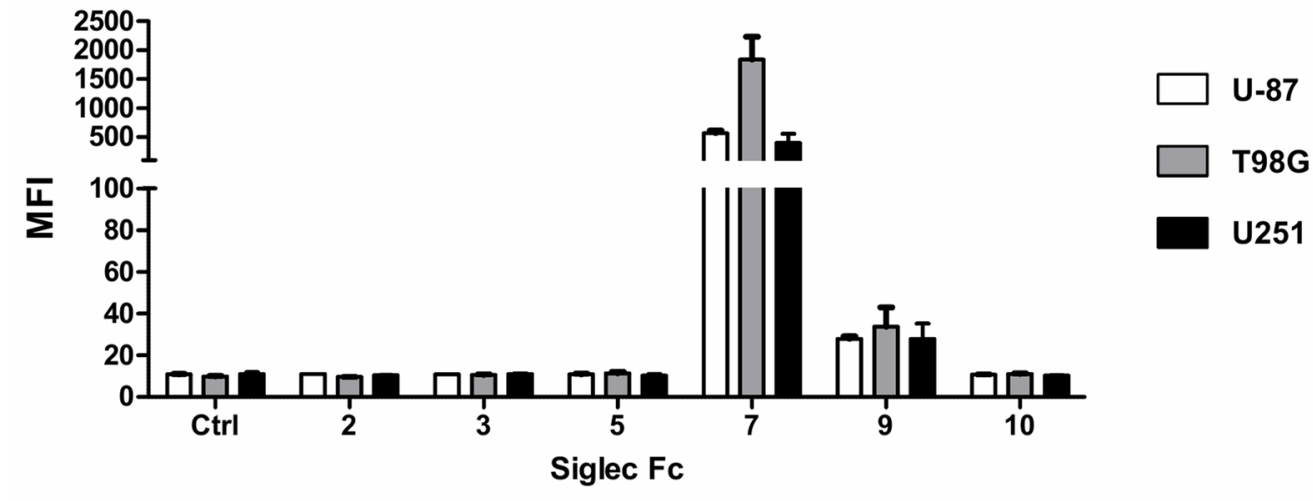

b

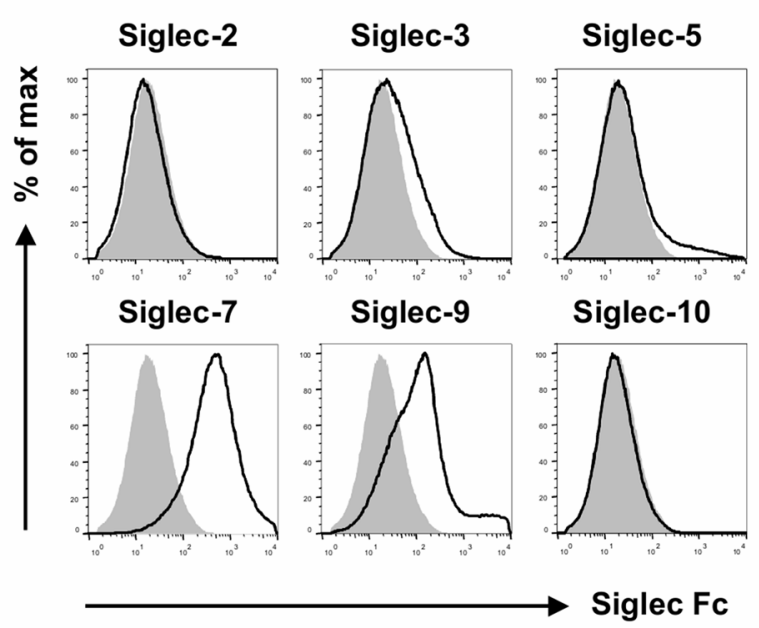

d

Isotype

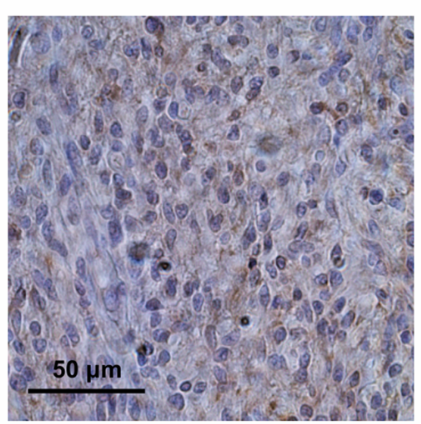

Siglec-7 Fc

C
Primary glioma cells

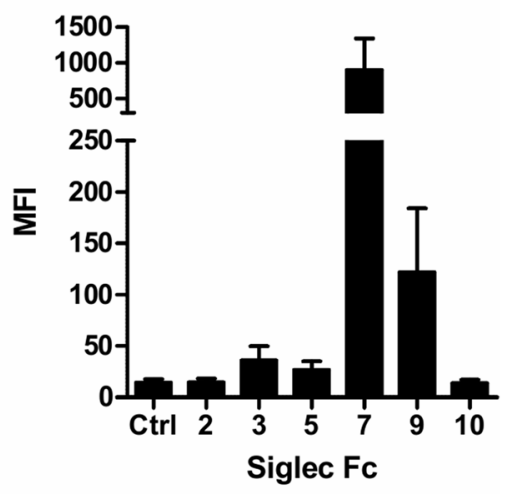

Siglec-9 Fc
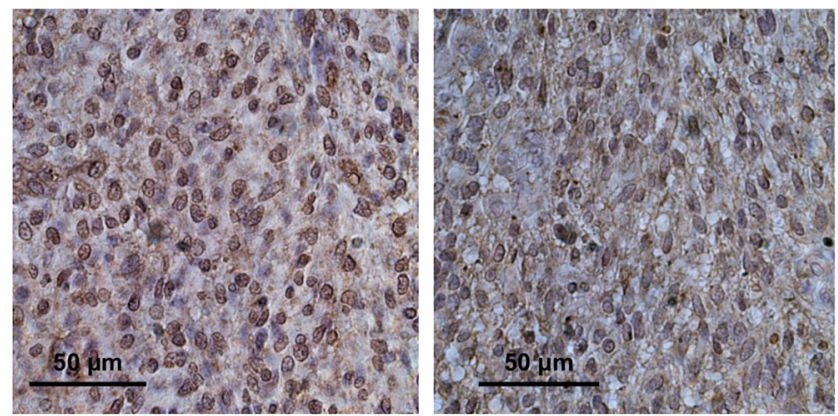

Siglec-7 Fc + sialidase

Siglec-9 Fc + sialidase
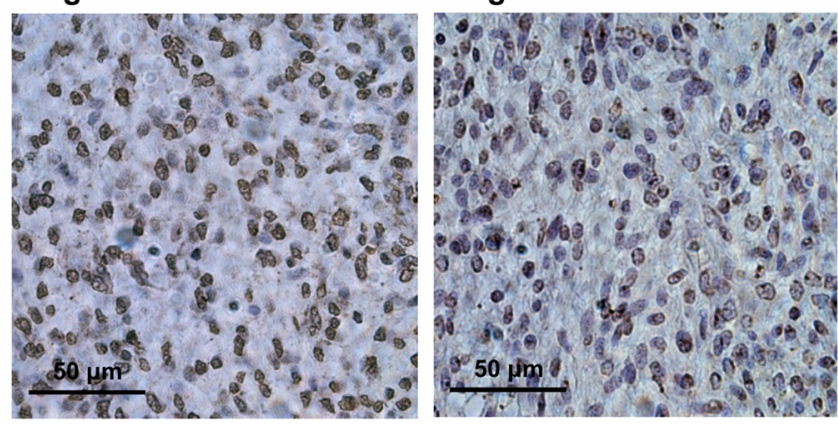
४Fig. 4 Glioma cell lines and freshly resected glioma cells express trans ligands for Siglecs. a Three glioblastoma cell lines were stained with recombinant Siglec Fc chimera and analyzed by flow cytometry. Bar diagrams show mean MFI \pm SEM of Siglec Fc chimera binding to U-87, T98G and U251 cells of three independent experiments. b, c Expression of Siglec ligands on glioma cells obtained from freshly resected tumor tissue (glioblastoma $n=1$, oligodendroglioma $n=3$ ). Representative histograms show binding of Siglec Fc chimera to $\mathrm{CD} 45^{-}$cells isolated from glioma tissue (b). Bar graphs show mean fluorescent intensity \pm SEM of Siglec Fc binding (c). d Immunohistochemistry for Siglec-7 and Siglec-9 ligand expression in paraffinembedded glioma tissue untreated (upper row) or treated with sialidase (lower row). Data are representative of 4 glioblastoma patients

lectins preferentially recognize $\alpha 2,3$-linked or $\alpha 2,6$-linked sialic acids or glycans without sialic acids, respectively. M-MDSCs and PMN-MDSCs were gated as shown in Fig. 1a and analyzed for lectin binding by flow cytometry. Both MDSC subsets expressed $\alpha 2,3$-linked and $\alpha 2,6$-linked sialic acids, with the highest levels on M-MDSCs (Fig. 3a, b). Interestingly, also PNA binding to M-MDSCs, but not to PMN-MDSCs could be observed, indicating the presence of uncapped glycans on these cells. Next, we investigated which Siglecs could potentially form $c$ is interactions with sialic acids present on the MDSCs. PBMCs from healthy donors were stained with recombinant human Siglec-Fc chimeras together with MDSC markers and analyzed by flow cytometry. From all Siglec-Fc chimeras tested, only Siglec-7 and Siglec-9 showed binding to both MDCS subsets, with Siglec-9 binding being the highest (Fig. 3c, d). In line with the plant-derived lectin stainings, M-MDSCs showed generally higher binding of Siglec-7 and -9 chimeras compared to PMN-MDSCs. Similar to the healthy donors, PMN-MDSCs from blood of glioma patients also expressed ligands for Siglec-7 and Siglec-9 (Fig. 3e, f). Here, the higher expression of Siglec-9 ligands compared to Siglec-7 ligands was not detected. Siglec-5 ligands were detected on PMN-MDSCs in 3 out of 5 glioma patients. No signal for Siglec-2, -3 or -10 binding was found. Altogether, our data show that both MDSC subsets express ligands for Siglec-7 and Siglec-9 that may form cis interactions with the corresponding Siglec receptors present on these cells.

\section{Glioblastoma cell lines and patient-derived glioma cells express trans Siglec ligands}

Many tumors show aberrantly high expression of sialic acid-carrying glycans that possibly interact with Siglecs expressed on MDSCs and other infiltrating immune cells. To investigate whether glioma cells express sialic acids that can serve as ligands for Siglecs, three different human glioblastoma cell lines (U-87, T98G and U251) were probed with recombinant human Siglec-Fc chimeras and analyzed by flow cytometry. While no staining of ligands for Siglec-2, $-3,-5$ and -10 was observed, ligands for Siglec-7 and -9 were detected on all three cell lines (Fig. 4a). Expression of Siglecs themselves on the cell surface of the glioma cell lines was not detected (data not shown).

Next, we investigated whether the results from glioblastoma cell lines resemble the Siglec ligand expression as it occurs on glioma cells in situ. Therefore, single cell suspensions were prepared from freshly isolated glioma tissue (from glioblastoma $n=1$ and oligodendrogliomas $n=3$ ) and stained with anti-CD45 antibody and recombinant human Siglec-Fc chimeras. Glioma cells were gated as single, viable cells lacking CD45 expression, the marker for infiltrating immune cells. On primary glioma cells, we mainly detected ligands for Siglec-7 and -9, while some patients also showed low levels of Siglec-3 and -5 ligand staining (Fig. 4b, c). The presence of the two most dominant ligands, for Siglec-7 and -9 , in glioma tissue was confirmed by immunohistochemistry (Fig. 4d). Specificity of Siglec-7 and -9 Fc chimera binding was confirmed by the loss of signal after hydrolysis of sialic acids by sialidase. Staining did not completely disappear, probably due to aspecific staining caused by the sialidase [42].

These data show that mainly sialic acid ligands for Siglec-7 and -9 are expressed by glioblastoma cell lines and on patient-derived glioma tissue. Interestingly, Siglec-7 and -9 were present on both MDSC subsets found in the blood and expression of Siglec-9 was also confirmed on PMNMDSCs from glioma tissue, suggesting possible trans interactions between glioma cells and MDSCs. In addition to MDSCs, other myeloid (regulatory) cells present in the tumor could interact with glioma cells via Siglec-7 and -9.

\section{Discussion}

The presence of MDSCs is increased in the blood of patients with glioma in a grade-dependent manner and they infiltrate the glioma tissue $[11,13]$. Siglec-3 is a widely used surface marker for MDSCs and has been suggested to promote MDSC expansion as well as their suppressive phenotype [18, 19, 21]. Expression of Siglec-3 on MDSCs was already well established, but expression of other Siglec family members on MDSCs has not been investigated so far. Here, we show that M-MDSCs and PMN-MDSCs isolated from the blood of glioma patients and healthy donors also express Siglec-5, -7 and -9 on their cell surface. M-MDSCs expressed higher Siglec-3, -7 and -9 levels compared to PMN-MDSCs, whereas Siglec-5 was highest on PMNMDSCs. Expression of Siglec-5 and -9 was also confirmed on PMN-MDSCs derived from glioma tissue. E-MDSCs have only low Siglec expression. Additionally, we showed that glioma cells mainly express ligands for Siglec-7 and -9. These data imply that sialic acid-Siglec interactions between 
glioma cells and PMN-MDSCs in the tumor microenvironment can occur that could influence MDSC function.

For Siglec-3, -5, -7 and -9, we found mRNA transcripts as well as cell surface protein expression on both MDSC subsets. In addition, expression of Siglec-11, -14 and -16 was found on the mRNA level, but their expression on the cell surface is not yet confirmed. Siglec-10 expression was detected by qPCR in both M-MDSC and PMNMDSCs, but protein expression could not be confirmed with the existing monoclonal antibodies. Also Siglec-6 and -8 membrane expression could not be detected. In general, M-MDSCs expressed higher levels of Siglecs compared to PMN-MDSCs, except for higher levels of Siglec-5 on PMN-MDSCs. Noteworthy, the antibody against Siglec-5 is cross-reactive to Siglec-14, but the higher expression of Siglec-5 in PMN-MDSCs was also found on mRNA level. The biological relevance of the different expression patterns of Siglec-3, -5, -7 and -9 between both MDSC subsets remains to be determined. In addition to the M- and PMN-MDSCs, we have also determined Siglec expression on the CD15-CD14- e-MDSCs. This population, however, is more prone to contamination by other cells, and therefore inclusion of the lineage markers CD3, CD19 and CD56 is important to characterize them as true lineage-negative MDSCs [14]. These lineage markers were not present in our MDSC panel and therefore, the levels of e-MDSCs found in our patients and controls might be an overestimation. We were able to include these lineage markers in four of our patients and could confirm low Siglec-3, -5 and -7 expressions on pure lineage-negative e-MDSCs. The limited numbers of patients and healthy donors included in this study preclude meaningful statements about possible differences between Siglec expression on MDSCs from patient(group) $\mathrm{s}$ or healthy donors.

In addition to expressing Siglec receptors, both MDSC subsets also expressed $\alpha 2,3$-linked and $\alpha 2,6$-linked sialic acids. M-MDSC showed overall higher expression levels of sialic acids compared with PMN-MDSCs. So far, the role of sialic acids in MDSC biology is largely unknown. Our findings suggest that these sialic acids could serve as cis or trans ligands for Siglec-5, -7 and -9 receptors on the surface of MDCS or other immune cell subsets interacting with MDSCs. Staining of MDSCs with recombinant Siglec-2, -3 and $-10 \mathrm{Fc}$ chimeras was negative, yet putative sialic acid ligands for these Siglecs could be masked [43]. Future studies should investigate the role of cis (MDSCs) and trans (tumor) sialic acid-Siglec interactions in MDSC biology and their relevance for cancer immunotherapy.

Most Siglecs have one or more ITIM motifs allowing them to modulate immune cell activation and function. In MDSCs, Siglec-3 signaling has been shown to induce secretion of suppressive cytokines after forming a functional ligand-receptor pair, for example, with S100A9 [19]. Whether this interaction is sialic acid dependent has not been investigated [19]. We have previously shown that serum from glioma patients contains increased levels of S100A8/9 compared to healthy individuals, suggesting that MDSCs in glioma patients could gain a more suppressive phenotype due to enhanced Siglec-3-S100A9 interactions [13]. On patient-derived glioma cells, we could only detect very low levels of ligands for Siglec-3; so, this is not very likely to affect MDSC function. In addition, we cannot detect Siglec-3 on intra-tumoral PMN-MDSCs, which could be caused by Siglec-3 downregulation or be a consequence of the isolation process. However, we did observe a clear expression of Siglec-7 and -9 ligands on glioma cells ex vivo as well as in situ and the corresponding Siglecs are present on both blood MDSCs and (at least Siglec-9) on tumor-infiltrated PMN-MDSCs. These findings indicate that glioma cells could, thus, interact with MDSCs via the sialic acid-Siglec-9 axis. It has been shown for other immune cell types that sialic acid-Siglec-7/-9 interactions can dampen immune cell activation or effector function thereby shaping the immunosuppressive tumor microenvironment [25, 29, 31-33, 35, 37, 44]. Further research needs to determine whether glioma sialic acids can indeed interact with Siglec-7 and -9 on MSDCs and/or other myeloid cells in the tumor microenvironment and what the functional consequences are.

In conclusion, our data show that MDSCs from glioma patients and healthy donors express Siglec-3, -5, -7 and -9. On patient-derived glioma cells, ligands are found for Siglec-7 and -9, supporting possible sialic acid-dependent interactions between glioma cells and MDSCs in the tumor microenvironment. It may be highly rewarding to further elucidate whether this interaction occurs in the tumor microenvironment and whether sialic acid-Siglec interactions influence the suppressive function of MDSCs. Such studies may provide new opportunities to interfere with MDSC function and may potentiate anti-glioma immunotherapy.

Author contributions KCMS, PRG, CB, BMS, PW and GJA designed the experiments. BK, SAJFHB, ML and PW contributed to the acquisition of the patient material and clinical data. KCMS, PR, CB and EDK-R performed the experiments. KCMS, PRG, CB, BMS, PW and GJA wrote the manuscript. All authors have critically revised the manuscript and read and approved the final version.

Funding This work was supported by grants from the STOP braintumors Foundation, COST (European Union), the Radboudumc grant awarded to Christian Büll, a grant from the Radboud Institute for Oncology to Gosse J. Adema and Pieter Wesseling and grants from the Dutch Cancer Society awarded to Gosse J. Adema and Christian 
Büll (KUN2015-7604) and Gosse J. Adema, Kim C.M. Santegoets and Pieter Wesseling (KWF11266).

\section{Compliance with ethical standards}

Conflict of interest The authors declare that they have no conflict of interest.

Ethical approval Experiments were performed in accordance to the Helsinki Declaration and approved by the local Medical Ethics Committee of the Radboudumc (registration number 2011/307).

Informed consent Informed consent was obtained from all individual participants included in the study. Patients consented to the use of their blood, tumor material and clinical data for research and publication. The healthy donors also consented to the use of their blood for research and publication.

Cell line authentication Human glioma cell lines U-87 (HTB-14), T98G (CRL-1690) and U-251 were obtained from the American Type Culture Collection (Manassas, VA). The phenotype of these cells was regularly checked; it did not change over time.

Open Access This article is distributed under the terms of the Creative Commons Attribution 4.0 International License (http://creativeco mmons.org/licenses/by/4.0/), which permits unrestricted use, distribution, and reproduction in any medium, provided you give appropriate credit to the original author(s) and the source, provide a link to the Creative Commons license, and indicate if changes were made.

\section{References}

1. Gielen PR (2016) The immunosuppressive network in patients with glioma; focus on the role of myeloid derived suppressor cells (doctoral thesis). Radboud umc, Nijmegen

2. Ho VK, Reijneveld JC, Enting RH, Bienfait HP, Robe P, Baumert BG, Visser O, Dutch Society for N-O (2014) Changing incidence and improved survival of gliomas. Eur J Cancer 50(13):23092318. https://doi.org/10.1016/j.ejca.2014.05.019

3. Sarkaria JN, Kitange GJ, James CD, Plummer R, Calvert H, Weller M, Wick W (2008) Mechanisms of chemoresistance to alkylating agents in malignant glioma. Clin Cancer Res 14(10):2900-2908. https://doi.org/10.1158/1078-0432.CCR-07-1719

4. Gousias K, Markou M, Arzoglou V, Voulgaris S, Vartholomatos G, Kostoula A, Voulgari P, Polyzoidis K, Kyritsis AP (2010) Frequent abnormalities of the immune system in gliomas and correlation with the WHO grading system of malignancy. J Neuroimmunol 226(1-2):136-142. https://doi.org/10.1016/j.jneur oim.2010.05.027

5. Grauer OM, Wesseling P, Adema GJ (2009) Immunotherapy of diffuse gliomas: biological background, current status and future developments. Brain Pathol 19(4):674-693. https://doi.org/10.11 11/j.1750-3639.2009.00315.x

6. Okada H, Kohanbash G, Zhu X, Kastenhuber ER, Hoji A, Ueda R, Fujita M (2009) Immunotherapeutic approaches for glioma. Crit Rev Immunol 29(1):1-42

7. Lim M, Xia Y, Bettegowda C, Weller M (2018) Current state of immunotherapy for glioblastoma. Nat Rev Clin Oncol 15(7):422442. https://doi.org/10.1038/s41571-018-0003-5

8. Gielen P, van der Valk P, Wesseling P (2014) Immune responses to tumours in the CNS. Neuroinflammation and CNS disorders.
Wiley, Hoboken, pp 363-384. https://doi.org/10.1002/97811 18406557.ch 15

9. Lindau D, Gielen P, Kroesen M, Wesseling P, Adema GJ (2013) The immunosuppressive tumour network: myeloid-derived suppressor cells, regulatory T cells and natural killer T cells. Immunology 138(2):105-115. https://doi.org/10.1111/imm.12036

10. Umansky V, Adema GJ, Baran J, Brandau S, Van Ginderachter JA, Hu X, Jablonska J, Mojsilovic S, Papadaki HA, Pico de Coana Y, Santegoets KCM, Santibanez JF, Serre K, Si Y, Sieminska I, Velegraki M, Fridlender ZG (2018) Interactions among myeloid regulatory cells in cancer. Cancer Immunol Immunother. https:// doi.org/10.1007/s00262-018-2200-6

11. Gielen PR, Schulte BM, Kers-Rebel ED, Verrijp K, PetersenBaltussen HMJM, ter Laan M, Wesseling P, Adema GJ (2015) Increase in both CD14-positive and CD15-positive myeloidderived suppressor cell subpopulations in the blood of patients with glioma but predominance of CD15-positive myeloid-derived suppressor cells in glioma tissue. J Neuropathol Exp Neurol 74(5):390-400. https://doi.org/10.1097/Nen.0000000000000183

12. Raychaudhuri B, Rayman P, Ireland J, Ko J, Rini B, Borden EC, Garcia J, Vogelbaum MA, Finke J (2011) Myeloid-derived suppressor cell accumulation and function in patients with newly diagnosed glioblastoma. Neuro-oncology 13(6):591-599. https ://doi.org/10.1093/neuonc/nor042

13. Gielen PR, Schulte BM, Kers-Rebel ED, Verrijp K, Bossman SA, Ter Laan M, Wesseling P, Adema GJ (2016) Elevated levels of polymorphonuclear myeloid-derived suppressor cells in patients with glioblastoma highly express S100A8/9 and arginase and suppress T cell function. Neuro-oncology 18(9):12531264. https://doi.org/10.1093/neuonc/now034

14. Bronte V, Brandau S, Chen SH, Colombo MP, Frey AB, Greten TF, Mandruzzato S, Murray PJ, Ochoa A, Ostrand-Rosenberg S, Rodriguez PC, Sica A, Umansky V, Vonderheide RH, Gabrilovich DI (2016) Recommendations for myeloid-derived suppressor cell nomenclature and characterization standards. Nat Commun 7:12150. https://doi.org/10.1038/ncomms12150

15. Cassetta L, Baekkevold ES, Brandau S, Bujko A, Cassatella MA, Dorhoi A, Krieg C, Lin A, Lore K, Marini O, Pollard JW, Roussel M, Scapini P, Umansky V, Adema GJ (2019) Deciphering myeloid-derived suppressor cells: isolation and markers in humans, mice and non-human primates. Cancer Immunol Immunother. https://doi.org/10.1007/s00262-019-02302-2

16. Lang S, Bruderek K, Kaspar C, Hoing B, Kanaan O, Dominas N, Hussain T, Droege F, Eyth C, Hadaschik B, Brandau S (2018) Clinical relevance and suppressive capacity of human myeloidderived suppressor cell subsets. Clin Cancer Res 24(19):48344844. https://doi.org/10.1158/1078-0432.CCR-17-3726

17. Raychaudhuri B, Rayman P, Huang PJ, Grabowski M, Hambardzumyan D, Finke JH, Vogelbaum MA (2015) Myeloid derived suppressor cell infiltration of murine and human gliomas is associated with reduction of tumor infiltrating lymphocytes. J NeuroOncol 122(2):293-301. https://doi.org/10.1007/s1106 0-015-1720-6

18. Gabrilovich DI, Nagaraj S (2009) Myeloid-derived suppressor cells as regulators of the immune system. Nat Rev Immunol 9(3):162-174. https://doi.org/10.1038/nri2506

19. Chen XH, Eksioglu EA, Zhou JM, Zhang L, Djeu J, Fortenbery N, Epling-Burnette P, Van Bijnen S, Dolstra H, Cannon J, Youn J, Donatelli SS, Qin DH, De Witte T, Tao JG, Wang HQ, Cheng PY, Gabrilovich DI, List A, Wei S (2013) Induction of myelodysplasia by myeloid-derived suppressor cells. J Clin Investig 123(11):4595-4611. https://doi.org/10.1172/JCI67580

20. Pillai S, Netravali IA, Cariappa A, Mattoo H (2012) Siglecs and immune regulation. Annu Rev Immunol 30:357-392. https://doi. org/10.1146/annurev-immunol-020711-075018 
21. Macauley MS, Crocker PR, Paulson JC (2014) Siglec-mediated regulation of immune cell function in disease. Nat Rev Immunol 14(10):653-666. https://doi.org/10.1038/nri3737

22. Bull C, Heise T, Adema GJ, Boltje TJ (2016) Sialic acid mimetics to target the sialic acid-siglec axis. Trends Biochem Sci 41(6):519-531. https://doi.org/10.1016/j.tibs.2016.03.007

23. Varki A, Crocker PR (2009) I-type lectins. In: Varki A, Cummings RD, Esko JD et al (eds) Essentials of glycobiology, 2nd edn. Cold Spring Harbor Laboratory Press

24. Varki A, Schauer R (2009) Sialic acids. In: Varki A, Cummings RD, Esko JD et al (eds) Essentials of glycobiology, 2nd edn. Cold Spring Harbor Laboratory Press

25. Miyazaki K, Sakuma K, Kawamura YI, Izawa M, Ohmori K, Mitsuki M, Yamaji T, Hashimoto Y, Suzuki A, Saito Y, Dohi T, Kannagi R (2012) Colonic epithelial cells express specific ligands for mucosal macrophage immunosuppressive receptors siglec-7 and -9. J Immunol 188(9):4690-4700. https://doi.org/10.4049/jimmu nol.1100605

26. Macauley MS, Pfrengle F, Rademacher C, Nycholat CM, Gale AJ, von Drygalski A, Paulson JC (2013) Antigenic liposomes displaying CD22 ligands induce antigen-specific B cell apoptosis. J Clin Investig 123(7):3074-3083. https://doi.org/10.1172/JCI69187

27. Macauley MS, Paulson JC (2014) Siglecs induce tolerance to cell surface antigens by BIM-dependent deletion of the antigen-reactive B cells. J Immunol 193(9):4312-4321. https://doi. org/10.4049/jimmunol.1401723

28. Bull C, Collado-Camps E, Kers-Rebel ED, Heise T, Sondergaard JN, den Brok MH, Schulte BM, Boltje TJ, Adema GJ (2017) Metabolic sialic acid blockade lowers the activation threshold of moDCs for TLR stimulation. Immunol Cell Biol 95(4):408-415. https://doi.org/10.1038/icb.2016.105

29. Büll C, den Brok MH, den Adema GJ (2014) Sweet escape: sialic acids in tumor immune evasion. Bba Rev Cancer 1846(1):238 246. https://doi.org/10.1016/j.bbcan.2014.07.005

30. Büll C, Stoel MA, den Brok MH, Adema GJ (2014) Sialic acids sweeten a tumor's life. Cancer Res 74(12):3199-3204. https://doi. org/10.1158/0008-5472.CAN-14-0728

31. Jandus C, Boligan KF, Chijioke O, Liu H, Dahlhaus M, Demoulins T, Schneider C, Wehrli M, Hunger RE, Baerlocher GM, Simon HU, Romero P, Munz C, von Gunten S (2014) Interactions between Siglec-7/9 receptors and ligands influence NK cell-dependent tumor immunosurveillance. J Clin Investig 124(4):1810-1820. https://doi.org/10.1172/JCI65899

32. Hudak JE, Canham SM, Bertozzi CR (2014) Glycocalyx engineering reveals a Siglec-based mechanism for NK cell immunoevasion. Nat Chem Biol 10(1):69-75. https://doi.org/10.1038/nchem bio. 1388

33. Beatson R, Tajadura-Ortega V, Achkova D, Picco G, Tsourouktsoglou TD, Klausing S, Hillier M, Maher J, Noll T, Crocker PR, Taylor-Papadimitriou J, Burchell JM (2016) The mucin MUC1 modulates the tumor immunological microenvironment through engagement of the lectin Siglec-9. Nat Immunol 17(11):12731281. https://doi.org/10.1038/ni.3552

34. Adams OJ, Stanczak MA, von Gunten S, Laubli H (2017) Targeting sialic acid-Siglec interactions to reverse immune suppression in cancer. Glycobiology. https://doi.org/10.1093/glycob/cwx108

35. Laubli H, Pearce OM, Schwarz F, Siddiqui SS, Deng L, Stanczak MA, Deng L, Verhagen A, Secrest P, Lusk C, Schwartz AG, Varki
NM, Bui JD, Varki A (2014) Engagement of myelomonocytic Siglecs by tumor-associated ligands modulates the innate immune response to cancer. Proc Natl Acad Sci USA 111(39):1421114216. https://doi.org/10.1073/pnas.1409580111

36. Bull C, Boltje TJ, Balneger N, Weischer SM, Wassink M, van Gemst JJ, Bloemendal VR, Boon L, van der Vlag J, Heise T, den Brok MH, Adema GJ (2018) Sialic acid blockade suppresses tumor growth by enhancing T-cell-mediated tumor immunity. Cancer Res 78(13):3574-3588. https://doi.org/10.1158/0008 5472.CAN-17-3376

37. Stanczak MA, Siddiqui SS, Trefny MP, Thommen DS, Boligan KF, von Gunten S, Tzankov A, Tietze L, Lardinois D, Heinzelmann-Schwarz V, von Bergwelt-Baildon M, Zhang W, Lenz HJ, Han Y, Amos CI, Syedbasha M, Egli A, Stenner F, Speiser DE, Varki A, Zippelius A, Laubli H (2018) Self-associated molecular patterns mediate cancer immune evasion by engaging Siglecs on $\mathrm{T}$ cells. J Clin Investig 128(11):4912-4923. https://doi.org/10.1172/ JCI120612

38. Louis DN, Ohgaki H, Wiestler OD, Cavenee WK (2016) World Health Organization histological classification of tumours of the central nervous system. International Agency for Research on Cancer, Lyon

39. Jacobs JFM, Idema AJ, Bol KF, Nierkens S, Grauer OM, Wesseling P, Grotenhuis JA, Hoogerbrugge PM, de Vries IJM, Adema GJ (2009) Regulatory T cells and the PD-L1/PD-1 pathway mediate immune suppression in malignant human brain tumors. Neuro-oncology 11(4):394-402. https://doi.org/10.1215/15228 517-2008-104

40. Schulte BM, Kers-Rebel ED, Prosser AC, Galama JMD, van Kuppeveld FJM, Adema GJ (2013) Differential susceptibility and response of primary human myeloid BDCA1(+) dendritic cells to infection with different enteroviruses. PLoS One 8:4. https://doi. org/10.1371/journal.pone.0062502

41. Spandidos A, Wang XW, Wang HJ, Seed B (2010) PrimerBank: a resource of human and mouse PCR primer pairs for gene expression detection and quantification. Nucleic Acids Res 38:D792D799. https://doi.org/10.1093/nar/gkp1005

42. Neves AA, Stockmann H, Harmston RR, Pryor HJ, Alam IS, Ireland-Zecchini H, Lewis DY, Lyons SK, Leeper FJ, Brindle KM (2011) Imaging sialylated tumor cell glycans in vivo. FASEB J 25(8):2528-2537. https://doi.org/10.1096/fj.10-178590

43. Razi N, Varki A (1998) Masking and unmasking of the sialic acidbinding lectin activity of CD22 (Siglec-2) on B lymphocytes. Proc Natl Acad Sci USA 95(13):7469-7474

44. Nicoll G, Avril T, Lock K, Furukawa K, Bovin N, Crocker PR (2003) Ganglioside GD3 expression on target cells can modulate NK cell cytotoxicity via siglec-7-dependent and -independent mechanisms. Eur J Immunol 33(6):1642-1648. https://doi. org/10.1002/eji.200323693

Publisher's Note Springer Nature remains neutral with regard to jurisdictional claims in published maps and institutional affiliations. 


\section{Affiliations}

Kim C. M. Santegoets ${ }^{1} \cdot$ Paul R. Gielen ${ }^{1} \cdot$ Christian Büll $^{1}$ - Barbara M. Schulte ${ }^{1} \cdot$ Esther D. Kers-Rebel $^{1}$. Benno Küsters $^{2} \cdot$ Sandra A. J. F. H. Bossman ${ }^{3} \cdot$ Mark ter Laan $^{3} \cdot$ Pieter Wesseling ${ }^{4,5} \cdot$ Gosse J. Adema $^{1}$

1 Radiotherapy and OncoImmunology Laboratory, Department of Radiation Oncology, Radboud Institute for Molecular Life Sciences, Radboud University Medical Center, Geert Grooteplein Zuid 32, 6525 GA Nijmegen, The Netherlands

2 Department of Pathology, Radboud University Medical Center, Nijmegen, The Netherlands

3 Department of Neurosurgery, Radboud University Medical Center, Nijmegen, The Netherlands
4 Department of Pathology, VU University Medical Center, Amsterdam, The Netherlands

5 Prinses Máxima Center for Pediatric Oncology and University Medical Center Utrecht, Utrecht, The Netherlands 